\title{
EFFECT OF SUPPLEMENTATION OF WITHANIA COAGULANS FRUIT ON THE FASTING PLASMA GLUCOSE LEVELS OF TYPE 2 DIABETIC SUBJECTS
}

\author{
HEMALATHA V, NORA VIGASINI* \\ Department of Home Science, Women's Christian College, Chennai, Tamil Nadu, India. Email: nora.researchpub@gmail.com
} Received: 21 May 2018, Revised and Accepted: 20 August 2018

\begin{abstract}
Objective: The objective of this study is to determine the effect of supplementation of Withania coagulans fruit on the fasting plasma glucose (FPG) levels of type 2 diabetic subjects.

Methods: In the natural system of medicine, many plants have been claimed to be useful for the management of diabetes mellitus. W. coagulans (Paneer poo) is one such source in which the fruit of the plant possesses hypoglycemic properties. The study was designed to determine the effect of a 60 -day supplementation of $W$. coagulans fruit drink on the FPG levels of Type 2 diabetic subjects. $W$. coagulans fruit (6 numbers - approximately 2.5 g) was soaked overnight in $100 \mathrm{ml}$ of water. This was administered to the experimental group. The control group received a placebo.
\end{abstract}

Results: There was a significant decrease in the FPG levels of the experimental group on the $61^{\text {st }}$ day. There was a statistically significant increase in the FPG level of the control group on the $61^{\text {st }}$ day, showing that the placebo did not have any hypoglycemic effect.

Conclusion: A significant reduction in FPG levels in the experimental group at the end of the study period proves that W. coagulans is a good hypoglycemic agent.

Keywords: Diabetes, Hypoglycemia, Withania coagulans, Fasting plasma glucose level.

(C) 2018 The Authors. Published by Innovare Academic Sciences Pvt Ltd. This is an open access article under the CC BY license (http://creativecommons. org/licenses/by/4. 0/) DOI: http://dx.doi.org/10.22159/ajpcr.2018.v11i12.27433

\section{INTRODUCTION}

Diabetes mellitus is a chronic disease which has clinched the world. $>300$ million people of the world are suffering from this disease, and the number is still increasing at a rapid rate as modern medical science has no permanent solution for the disease [1]. It is a complicated and divergent metabolic disorder which in addition to blood sugar control requires the management of lipid parameters, blood pressure, and thrombotic factors. The treatment for diabetes is both difficult and tedious; it is expensive and unaffordable by majority of the population [2].

The current treatments for diabetes mellitus include the use of insulin and synthetic drugs. The long-term usage of modern drugs exhibits several side effects and complications to different organs of the body which ultimately lead to cardiovascular problems, liver disease, kidney disease, and weight gain too. These synthetic drugs are valuable but restricted by their side effects such as hypoglycemia, damage to the liver, lactic acidosis, diarrhea, abdominal pain, weight loss, and loss of appetite $[2,3]$.

Due to the problems associated with the current treatments, a large percentage of diabetics resort to natural plant-based alternative remedies that are supposed to improve glycemic control. Hence, there is a need to screen more medicinal plants that have the advantage of being biodegradable, safe, and cheap with fewer side effects for their hypoglycemic activity [3].

The World Health Organization has pointed out that prevention of diabetes and its complications is a major global challenge. Therefore, in recent years, considerable attention has been directed toward identification of plants with antidiabetic ability that may be used for human consumption [4]. Withania coagulans (Paneer poo) is one such source, in which every part of the plant possesses therapeutic properties. It has many bioactive compounds that are responsible for its biological and pharmacological activities. Besides phenols, flavonoids, tannins, saponins, and alkaloids, the withanolides present in it are the major bioactive components that possess antimicrobial, anti-inflammatory, antitumor, hepatoprotective, antihyperglycemic, cardiovascular, immunosuppressive, and free radical scavenging properties. It is commonly available in herbal shops, less expensive with no reported side effects and toxicity $[5,6]$.

Therefore, this study aimed at evaluating the role of $W$. coagulans fruit as an adjunct hypoglycemic agent which probably might throw some light on its potential use as a natural, cost-effective, and safe therapeutic alternative in the management of type 2 diabetes mellitus.

\section{Objective of the study}

The objective of this study is to determine the effect of supplementation of $W$. coagulans fruit drink on the fasting plasma glucose (FPG) levels of type 2 diabetic subjects.

\section{METHODS}

The approval of the Institutional Ethics Committee was obtained before the conduction of the study.

\section{Design of the study}

The research design adopted for this study was a pre-test, post-test experimental research design with control group. The study was carried out to determine the effect of supplementation of $W$. coagulans on the FPG levels of 12 type 2 diabetic subjects. Assessments were made on $0^{\text {th }}, 30^{\text {th }}$, and $61^{\text {th }}$ days of study/supplementation. The same parameters were assessed among 12 other type 2 diabetic subjects who served as the control group. The control group received a placebo.

\section{Selection of the sample}

The subjects were selected based on purposive sampling. Both male and female type 2 diabetic subjects aged between 35 and 65 years were selected after an initial screening. The subjects were selected from North Chennai. 


\section{Criteria for sample selection}

\section{Inclusion criteria}

The following criteria were included in the study:

- Male and female type 2 diabetic subjects aged between 35 and 65 years.

- Subjects with FPG levels $>126 \mathrm{mg} / \mathrm{dl}$ [7].

- Subjects taking oral hypoglycemic drugs.

- Willingness of the subjects to participate in the study.

\section{Exclusion criteria}

The following criteria were excluded from the study:

- Individuals with type 1 diabetes mellitus.

- Individuals with complications such as cancer, thyrotoxicosis, chronic renal failure, peptic ulcer, and other diabetes-related complications.

- Smokers and alcoholics.

- Subjects on insulin injections.

- Pregnant and lactating women.

Subjects were randomly assigned to either the control or the experimental groups that comprised of 12 subjects each (Fig. 1).

\section{Orientation of the subjects}

The subjects were briefed about the significance of the study by the investigator. They were instructed that blood would be collected in a 12-h fasting state to assess the FPG levels of the subjects. The subjects were requested to report between $6.30 \mathrm{am}$ and $8.00 \mathrm{am}$ in a 12-h fasting state for blood collection on the $0^{\text {th }}$ day of the study/ supplementation period. The initial FPG levels of all the subjects were analyzed, and they were divided into two groups, namely, the control group and the experimental group. Both groups continued with their oral hypoglycemic drugs during the supplementation period.

\section{Collection of blood sample}

$2 \mathrm{ml}$ of blood was drawn from antecubital vein using a $2.5-\mathrm{mL}$ sterile disposable syringe with $23-\mathrm{G} \times 1$ needle. The blood was drawn from each subject and then transferred into separate fluoride tubes. It was mixed by inverting the tube $8-10$ times. Then, the tubes were centrifuged at $3000 \mathrm{rpm}$ for $10 \mathrm{~min}$. The plasma was aspirated and used for glucose analysis. This procedure was adopted for the initial screening $\left(0^{\text {th }}\right.$ day $)$ and repeated on the $30^{\text {th }}$ and $61^{\text {st }}$ days of supplementation.

\section{Preparation of supplement}

W. coagulans fruit can be used effectively in the long-term management of type 2 diabetes mellitus without any side effects. A supplementation of $10 \mathrm{~g}$ of $W$. coagulans for 3 months has been reported to be safe without any side effects or toxicity $[8,9]$.

In this study, six fruits (around 2-2.5 g) of W. coagulans (paneer poo) were soaked overnight in $100 \mathrm{ml}$ of water. In the morning, the fruits were squeezed into the water. The extract was filtered, and to this, $1 \mathrm{ml}$ of tamarind extract was added and administered. A photograph of the W. coagulans drink (supplement) is shown in Fig. 2.

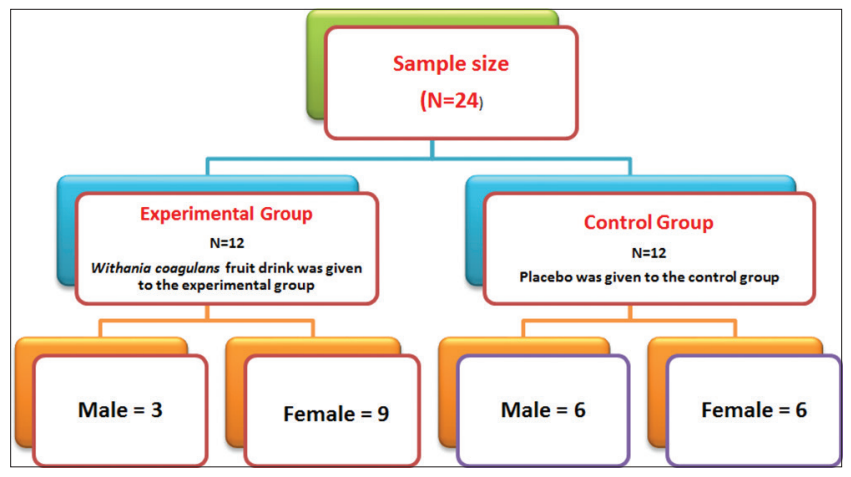

Fig. 1: Sample size

\section{Preparation of placebo}

As shown in Fig. 3, W. coagulans supplement had a yellowish to light brown tint. To give a similar appearance for the placebo that was administered to the control group, $1 \mathrm{ml}$ of tamarind fruit pulp was added to $100 \mathrm{ml}$ of water.

\section{Control group}

$1 \mathrm{ml}$ of tamarind fruit pulp in $100 \mathrm{ml}$ of water served as the placebo which the control group had to consume every morning at 6.30 AM in an empty stomach.

\section{Experimental group}

Subjects in the experimental group were instructed to take the supplement every morning at 6.30 AM in an empty stomach.

\section{RESULTS AND DISCUSSION}

Effect of supplementation of $W$. coagulans on FPG levels of Type 2 diabetic subjects

The FPG levels of subjects in the experimental and control groups assessed on the day before the commencement of supplementation $\left(0^{\text {th }}\right.$ day), on the $30^{\text {th }}$ day of supplementation, and on the day after the last day of supplementation (61 $1^{\text {st }}$ day) are presented in Table 1 and Fig. 4.

It can be observed from Table 1 that there was a significant decrease in the FPG levels in the experimental group on the $30^{\text {th }}$ and $61^{\text {st }}$ days. A highly significant reduction in FPG levels in the experimental group at the end of the study period proves that $W$. coagulans has a good hypoglycemic effect. This hypoglycemic effect of $W$. coagulans can be attributed to the bioactive compounds such as phenol, flavonoid, and withanolides present in it.

It is evident from Table 1 that there was a decrease in the mean FPG levels of the control group on the $30^{\text {th }}$ day; however, this was not statistically significant. A different trend was observed after this period, where there was a statistically significant increase in the FPG level in the control group on the $61^{\text {st }}$ day. This proves that the placebo did not have any hypoglycemic effect.

It has been reported that the hydroalcoholic extract of $W$. coagulans and the cold aqueous extract of $W$. coagulans exhibit antihyperglycemic activities in alloxan-induced diabetic rats [10].

Effect of supplementation on FPG Levels of subjects - experimental versus control group

A comparison of the FPG levels of the experimental and control group between the $0^{\text {th }}$ and $61^{\text {st }}$ days of the study is presented in Table 2 .

On comparing the mean FPG levels of the experimental and control groups on the day before the commencement of supplementation ( $0^{\text {th }}$ day), it was found that there was no statistically significant difference between the two groups.

However, at the end of the supplementation period ( $61^{\text {st }}$ day), there was a statistically significant difference between the experimental

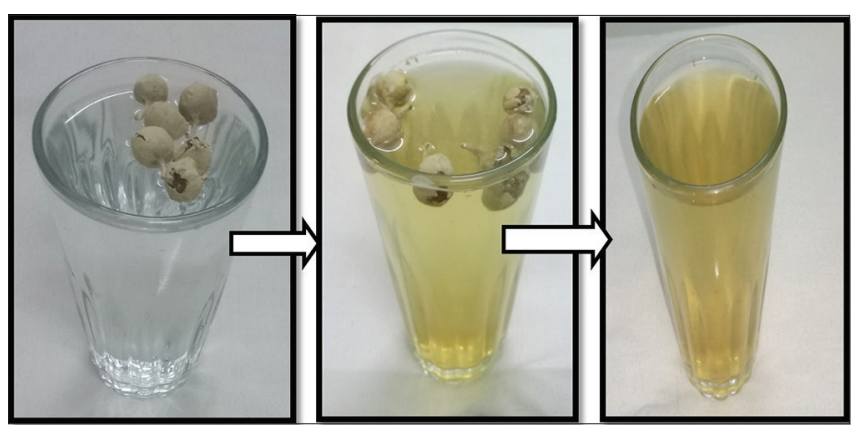

Fig. 2: Withania coagulans fruit drink (supplement) 
Table 1: FPG levels of subjects in the experimental and control groups

\begin{tabular}{|c|c|c|c|c|c|c|c|c|c|}
\hline \multirow[t]{3}{*}{ Parameter } & \multicolumn{7}{|c|}{ Experimental group } & & \\
\hline & \multirow{2}{*}{$\begin{array}{l}0^{\text {th }} \text { day } \\
\text { Mean } \pm \text { SD }\end{array}$} & \multirow{2}{*}{$\begin{array}{l}30^{\text {th }} \text { day } \\
\text { Mean } \pm S D\end{array}$} & \multirow{2}{*}{$\begin{array}{l}61^{\text {st }} \text { day } \\
\text { Mean } \pm S D\end{array}$} & \multicolumn{2}{|c|}{$0^{\text {th }}$ versus $30^{\text {th }}$ day } & \multicolumn{2}{|c|}{$30^{\text {th }}$ versus $61^{\text {st }}$ day } & \multicolumn{2}{|c|}{$0^{\text {th }}$ versus $61^{\text {st }}$ day } \\
\hline & & & & “ $\mathrm{t}^{\prime}$ & Significance & "t" & Significance & “t” & Significance \\
\hline \multirow[t]{2}{*}{$\begin{array}{l}\text { FPG level } \\
\text { (mg/dl) }\end{array}$} & $188.75 \pm 64.93$ & $163.33 \pm 44.77$ & $134.08 \pm 38.58$ & 3.64 & $\begin{array}{l}0.004^{* *} \\
(\mathrm{p}<0.01)\end{array}$ & 3.54 & $0.005^{* *}(\mathrm{p}<0.01)$ & 3.78 & $0.003^{* *}(\mathrm{p}<0.01)$ \\
\hline & $\begin{array}{l}\text { Control group } \\
181.33 \pm 67.85\end{array}$ & $169.41 \pm 45.71$ & $207.25 \pm 60.30$ & 1.17 & $0.264 \mathrm{NS}$ & 4.54 & $0.001^{* *}(\mathrm{p}<0.01)$ & 3.05 & $0.011^{* *}(\mathrm{p}<0.01)$ \\
\hline
\end{tabular}

NS: Not significant, ${ }^{* *}$ Significant at $\mathrm{p}<0.01$. SD: Standard deviation, FPG: Fasting plasma glucose

Table 2: Comparison of FPG levels of subjects (experimental group versus control group - $0^{\text {th }}$ versus $61^{\text {st }}$ day)

\begin{tabular}{|c|c|c|c|c|c|c|c|c|}
\hline \multirow[t]{4}{*}{ Parameter } & \multicolumn{8}{|c|}{ Experimental group versus control group } \\
\hline & \multicolumn{4}{|l|}{$0^{\text {th }}$ day } & \multicolumn{4}{|l|}{$61^{\text {th }}$ day } \\
\hline & \multirow{2}{*}{$\begin{array}{l}\text { Experimental } \\
\text { group } \\
\text { Mean } \pm \text { SD }\end{array}$} & \multirow{2}{*}{$\begin{array}{l}\text { Control } \\
\text { group } \\
\text { Mean } \pm \text { SD }\end{array}$} & \multicolumn{2}{|c|}{ Level of significance } & \multirow{2}{*}{$\begin{array}{l}\text { Experimental } \\
\text { group }\end{array}$} & \multirow{2}{*}{$\begin{array}{l}\text { Control } \\
\text { group }\end{array}$} & \multicolumn{2}{|c|}{ Level of significance } \\
\hline & & & “t” & Significance & & & “t” & Significance \\
\hline $\begin{array}{l}\text { Fasting plasma glucose } \\
\text { level (mg/dl) }\end{array}$ & $188.75 \pm 64.93$ & $181.33 \pm 67.85$ & 0.27 & $0.787 \mathrm{NS}$ & $134.08 \pm 38.58$ & 207.2560 .30 & 3.54 & $0.002(\mathrm{p}<0.01)^{* *}$ \\
\hline
\end{tabular}

NS: Not significant, ${ }^{* *}$ Significant at $\mathrm{p}<0.01$. SD: Standard deviation, FPG: Fasting plasma glucose

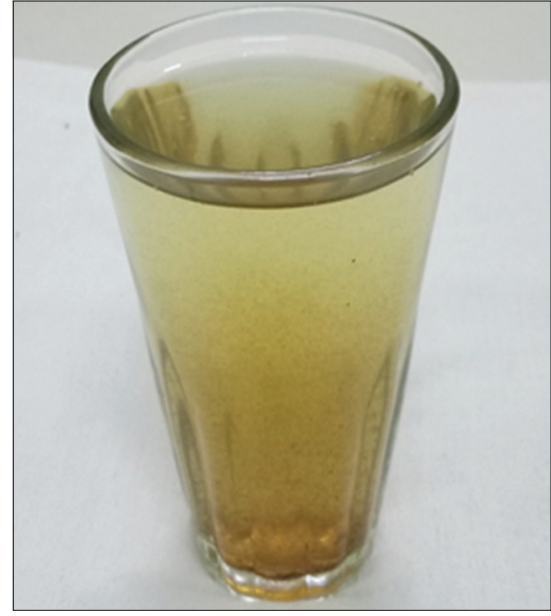

Fig. 3: Placebo drink

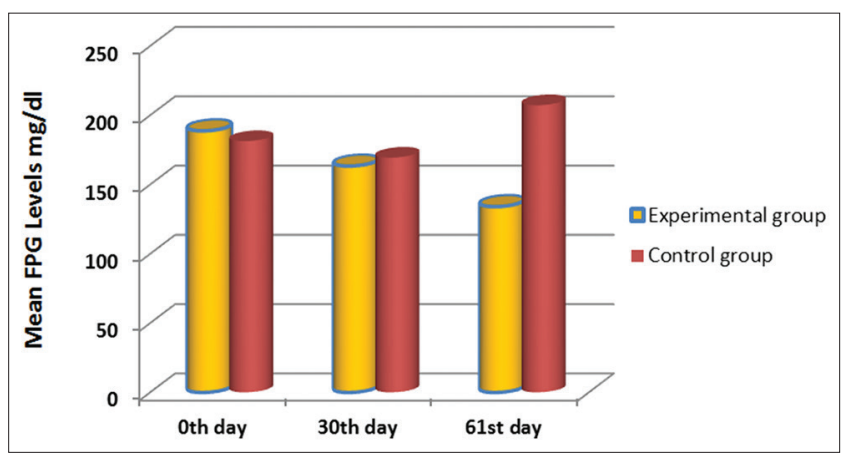

Fig. 4: Effect of supplementation of Withania coagulans on fasting plasma glucose levels of type 2 diabetic subjects

and control groups. The experimental group showed a decrease while the control group showed an increase in the FPG levels that were statistically significant.

It has been reported that $W$. coagulans (Doda Paneer) not only lowers the blood sugar level but also minimizes the future complications of diabetes such as neuropathy, retinopathy, nephropathy, and cardiovascular pathologies by its very potent antioxidant action [11].

\section{CONCLUSION}

The findings of this study strongly support the fact that the fruit of $W$. coagulans fruit (Paneer poo) may be used as a potent, natural, plantbased, non-toxic, adjunct hypoglycemic agent in the management of diabetes. The bioactive components in the fruit may be extracted and used by the pharmaceutical industry for preparing plant-based drugs for diabetes that have no side effects.

\section{AUTHORS' CONTRIBUTIONS}

The first author (V. Hemalatha) is the principal investigator of the work, who reviewed the article, collected the sample, and performed the experiment. The corresponding author (Nora Vigasini) supervised the entire study by designing the methodology and helping in manuscript writing.

\section{CONFLICTS OF INTEREST}

The authors declare that they have no conflicts of interests.

\section{REFERENCES}

1. Dimple, Kumar A, Kumar V, Vidisha T. Traditional medicinal systems for treatment of diabetes mellitus: A review. Int J Pharm Pharm Sci 2018;10:7-17.

2. Mohammed A, Kumar D, Rizvi SI. Antidiabetic potential of some less commonly used plants in traditional medicinal systems of India and Nigeria. J Intercult Ethnopharmacol 2015;4:78-85.

3. Kalsi A, Singh S, Taneja N, Kukal S, Mani S. Current treatments for Type 2 diabetes, their side effects and possible complementary treatments. Int J Pharm Pharm Sci 2014;7:13-8.

4. Demain AL, Sanchez S. Microbial drug discovery: 80 years of progress. J Antibiot (Tokyo) 2009;62:5-16.

5. World Health Organization. Definition and Diagnosis of Diabetes Mellitus and Intermediate Hyperglycaemia: Report of a WHO/IDF Consultation. Geneva: World Health Organization; 2006.

6. Gupta PC. Withania coagulans dunal-an overview. Int J Pharm Sci Rev Res 2012;12:68.

7. Jaiswal D, Rai PK, Watal G. Antidiabetic effect of Withania coagulans in experimental rats. Indian J Clin Biochem 2009;24:88-93.

8. American Diabetes Association Standards of Medical Care in Diabetes. J Clin Appl Res Educ 2016;39 Suppl 1

9. Upadhyay BN, Gupta VA. Clinical study on the effect of rishyagandha (Withania coagulans) in the management of prameha (Type II diabetes 
mellitus). Int Q J Res Ayurveda 2011;32:507-11.

10. Madan TB. Review of rushyagandha. Int Ayurvedic Med J 2015;3:1158-60.

11. Yasir M, Shrivastava R, Jain P, Das D. Hypoglycemic and antihyperglycemic effects of different extracts and combinations of
Withania coagulans dunal and Acacia arabica Lamk in normal and alloxan induced diabetic rats. Pharmacogn Commun 2012;2:61-6.

12. Vaibhav A, Singh OP, Tiwari SK. Withania coagulans-an overview with special reference to diabetes mellitus. Indian J Res 2012;7:1-6. 